\title{
TRADUÇÃO NO ENSINO DE ESP NO BRASIL: UMA ANÁLISE FOCADA NA PERCEPÇÃO DE PROFESSORES
}

\author{
Carla Alecsandra de Melo Bonifácio é Doutora em Linguística e Professora Adjunta da UFPB. \\ E-mail: carla.bonifacio@ @otmail.com \\ Marcus Vinícius Freitas Mussi é Mestre em Linguística Aplicada e Pesquisador Associado do Laboratório de Tecnologia da Informação e da \\ Comunicação da UFRJ. \\ E-mail: marcusmussi@gmail.com
}

\begin{abstract}
Resumo
O presente artigo visa discutir a percepção de professores de inglês a respeito da relação entre tradução e ensino de ESP (English for Specific Purpose) no Brasil. Para isso, foram adotados o paradigma interpretativista como abordagem de pesquisa e questionários online aplicados com professores brasileiros como instrumentos de coleta de dados. As respostas dadas satisfizeram todos os questionamentos de pesquisa, ratificando o propósito em realizá-la
\end{abstract}

\begin{abstract}
This article aims to discuss the perception of English professors about the relation between translation and teaching of ESP (English for Specific Purpose) in Brazil. In order to do so, the qualitative paradigm was adopted as research approach, and questionnaires were applied with Brazilian professors as data collection tools. The given answers satisfied all research questions, ratifying the purpose of making it.
\end{abstract}

\section{1) Considerações Iniciais}

Ao longo dos anos, muito se tem discutido sobre o papel da tradução no ensino de uma língua estrangeira (LE). Isso se deve ao fato das várias mudanças ocorridas com a tradução, uma vez que, primeiramente, ela foi o pilar do Método Gramática-Tradução (MGT), depois foi banida pelo chamado Método Direto e atualmente retorna, ainda que lentamente, a ocupar um posto de auxiliar do professor de línguas.

Se por um lado, a tradução apresenta diversos benefícios e vantagens para aulas de idiomas, por outro lado, certas crenças de professores, sobretudo os que atuam no ensino de ESP no Brasil (motivos legados do Projeto ESP, que veremos no terceiro item), podem levar ao impedimento de se adotar tradução como um instrumento para suas aulas. Tal impasse motivou a investigação desta pesquisa, que foi norteada pelas seguintes questões: Quais são as crenças de professores de ESP em relação ao uso de tradução em suas aulas no contexto brasileiro? Quais as perspectivas para o uso de tradução em aulas de ESP?

Portanto, o principal propósito deste artigo é identificar e analisar crenças e perspectivas de professores que atuam no Brasil em relação ao ensino de tradução em aulas de English for Specific Purpose (doravante ESP). O aporte teórico no que diz respeito ao ESP e à tradução tem por base os trabalhos desenvolvidos por Celani (1988); Ramos (2005); Ross (2000); Stoddart (2000); T. Dudley-Evans \& M.J. St. John (1998) e Swales 
(1984), já em relação à metodologia, o embasamento é fundamentado em Allwright e Bailey (1991); Bruner (1997); Chizzotti (2003); Hryniewiewicz (1999); McDonough \& McDonough (1997); Magalhães (1994) e Ludke \& André (1986).

É necessário ainda salientar que, embora existam, no meio acadêmico, artigos que abordem tanto o ensino de ESP no Brasil, quanto o ensino de tradução em língua estrangeira, este artigo se justifica pela possibilidade de análise do uso da tradução no ensino de ESP com foco na percepção de professores, por se tratar de um estudo de cunho interpretativista. Sem dúvida, as contribuições dos pesquisadores nesses artigos são inúmeras, mas ainda há muito a ser feito e considerado. No que diz respeito à tradução no ensino de ESP no Brasil, há possibilidades reais de cooperações nesses estudos, de forma que é socialmente relevante colaborar com pesquisas que estão em desenvolvimento. Isso porque, não se pretende aqui, apenas aplicar teorias adotadas, mas repensar práticas sociais com o intuito de contribuir para o direcionamento de pesquisas com investigações similares.

Para uma melhor organização e foco neste trabalho, centraremos nossa atenção nos seguintes pontos: 1) Considerações iniciais, 2) Procedimentos Metodológicos, 3) Ensino de ESP no Brasil, 4) Desafios e Perspectivas para Tradução no Ensino de ESP, 5) Análise e Resultados, 6) Considerações Finais

\section{2) Procedimentos Metodológicos}

No que se refere aos procedimentos metodológicos, optamos por utilizar o paradigma interpretativista (qualitativo) em detrimento do paradigma positivista (quantitativo), além de entrevistas semiestruturadas online como instrumentos de coleta de dados.

Isso porque, por um lado, o positivismo está associado a julgamentos "objetivos" feitos por pesquisadores de "fora" do contexto e tendem a isolar os fatos que são verdades para mais pessoas do que a pesquisa mostra. Além disso, seus efeitos isolados são causados por natureza e o objetivo de tal perspectiva é levantar relações de causa e efeito válidas como ocorre nas ciências naturais (McDonough and McDonough, 1997).

Por outro lado, as pesquisas interpretativistas são caracterizadas por sugerir soluções alternativas para os problemas a partir do contexto, de generalizações e convicção nas conclusões. Oferecem cânones de rigor metodológico à investigação local e a problemas em pequena escala de comunidades. Isso pode ser observado em Mac Donough e Mac Donough (1997). Estão "embasadas não apenas no que as pessoas realmente fazem, mas no que elas dizem que fazem e no que elas dizem que as fez fazer o que elas fizeram" (Bruner, 1997, p.25); além de o pesquisador e o "outro" serem co-participantes ativos e sujeitos no 
ato de construção e de transformação do conhecimento. Tal observação pode ser encontrada em Magalhães (1994). Sobre o termo qualitativo Chizzotti (2003) afirma que ele:

[...] Implica uma partilha densa com pessoas, fatos e locais que constituem objetos de pesquisa, para extrair desse convívio os significados visíveis e latentes que somente são perceptíveis a uma atenção sensível e, após este tirocínio, o autor interpreta e traduz em um texto, zelosamente escrito, com perspicácia e competência científica, os significados patentes ou ocultos do seu objeto de pesquisa. (Chizzotti, 2003, p.1)

Dessa forma, foi adotado aqui o paradigma interpretativista por este trabalho ter investigado os significados da percepção do que as pessoas fazem e dizem que fazem. Além disso, trata-se de uma investigação local em que o pesquisador e o entrevistado são co-participantes ativos. Por outro lado, não se pretendeu buscar respostas objetivas ou analisar fatos isolados do contexto. Concomitante ao paradigma de pesquisa, foi preciso fazer escolhas, também, em relação aos instrumentos de pesquisa.

Neste sentido, Allwright e Bailey (1991) alertam que antes de começar a coletar e analisar os dados, é importante que os pesquisadores tenham consciência das suas predisposições e sua base de dados. Segundo McDonough e McDonough (1997), o pesquisador possui certa variedade de instrumentos de geração/coleta de dados, tais como: observações, entrevistas, gravações de dados de campo, transcrições, entre outros.

Dentre essas possibilidades, a entrevista semiestruturada online foi adotada como instrumento de geração/coleta de dados para esta pesquisa pelo fato de os questionários serem instrumentos limitados, de acordo com Brandão (2002). Além disso, segundo Ludke \& André, (1986) a semiestruturação oferece liberdade para se realizar adequações e novos esclarecimentos durante sua aplicação. E, finalmente, online pela facilidade e sociabilidade na interação entre pesquisador e professor, como podemos corroborar através da seguinte citação:

Não só o e-mail fornece um instrumento fácil para estar ali à distância, como torna mais fácil marcar presença sem se envolver numa interação mais profunda para a qual não se dispõe de energia emocional naquele dia. (...) Mas o papel mais importante da Internet na estruturação de relações sociais é sua contribuição para o novo padrão de sociabilidade baseado no individualismo. (Castells, 2003, p.109).

E para análise de dados adotamos as perspectivas de Spradley (1979) e Erickson (1988) por postularem que a análise de dados não deve ser um procedimento isolado, mas uma prática que interage com outros procedimentos da pesquisa, e que ocorre desde a reflexão sobre os temas propostos até a revisão do trabalho de coleta de dados. 
Dessa forma, esta pesquisa de cunho interpretativista foi conduzida a partir da coleta de dados através de entrevistas semiestruturadas online, e a análise desses dados foi realizada de forma gradual. Mas, sobretudo sob a constante fiscalização ética, visto que, segundo Paiva (2005), já é uma preocupação em todas as áreas da ciência. Assim, após justificarmos os procedimentos metodológicos adotados aqui, serão apresentados no próximo tópico possíveis conceitos de ESP e tradução, além de um breve histórico do ensino de ESP no Brasil.

\section{3) Ensino de ESP no Brasil}

Antes de situarmos historicamente o ensino de ESP no Brasil, faz-se necessário, primeiramente, conceituarmos o termo. Segundo Celani (1988), em nosso país o ESP, cuja tradução é "inglês para fins específicos", é conhecido como inglês instrumental. Mas o que é exatamente ESP? Dudley-Evans e St. John (1998) definem ESP como um tipo de ensino de Língua Inglesa (ELT) que trata das necessidades e práticas comunicativas particulares de um profissional ou grupo ocupacional. Dito de outra maneira, é um ensino personalizado para determinado perfil. De acordo com estes autores, ESP está tradicionalmente dividido em duas grandes áreas, ambas investigadas neste trabalho: inglês para fins acadêmicos (EAP) e inglês para fins profissionais (EOP).

O ensino de línguas estrangeiras não é um campo de atuação recente, pois segundo Alessi e Mareco (2009), remonta da época dos impérios grego e romano. No entanto, de acordo com Alessi (2011), os estudos de língua para fins específicos só se dá no século XVI, mesmo período em que surgem os primeiros métodos (ou abordagens, segundo Leffa, 1998) do ensino de língua inglesa, como pode ser observado em Leffa (1988). Assim como a obra Curso de Linguística Geral (1916) do estruturalista Ferdinand de Saussure é assinalada, segundo Silva (2008) como o ponto que marca o reconhecimento da Linguística como ciência, o trabalho de Charles Barber Some Measurable Characteristics of Modern Scientific Prose (1962), de acordo com Swales (1984), pode ser considerado o ponto de partida para estudos modernos de línguas para fins específicos.

No Brasil, o ensino de ESP tem como marco inicial o Projeto ESP nas universidades que, na década de 1970, surgiu para atender as necessidades de se ministrar inglês para diversos departamentos, sendo identificada neste contexto a leitura como a principal necessidade. Tal projeto foi fruto de um intercâmbio entre Brasil e exterior, e seu sucesso se deu em grande parte pelo fato de não ter sido um treinamento, mas sim fundamentado em uma perspectiva de cooperação, debates, reflexões e, sobretudo, por considerar as especificidades locais, caracterizando-se assim, como uma fusão do global e local, como podemos notar em Celani (1988). 
A partir do acolhimento dos participantes do projeto em relação ao inglês instrumental e discussões em seminários e workshops, foi possível configurar uma abordagem de ensino de inglês instrumental com características particularmente brasileiras, cujo foco estava no desenvolvimento de estratégias de leitura e no uso da língua materna do aprendiz durante o processo de ensino/aprendizagem. Segundo Bomfim (2006), níveis de compreensão textual, vocabulário e gramática são alguns exemplos de aspectos abordados nestes cursos.

Posteriormente, o inglês instrumental se expandiu para várias outras instituições de nível superior privadas e públicas que não faziam parte do projeto, também para escolas técnicas. Atualmente, é utilizado em cursos preparatórios para vestibular, para concursos públicos, para seleção de mestrado e doutorado, também em algumas escolas de ensino fundamental e médio, como pode ser observado em Bomfim (2006). Essa expansão se deve não só pelo sucesso do projeto mencionado, como também por atender às necessidades específicas do aprendiz através de uma linguagem contextualizada, como podemos também notar em Bomfim (2006). De acordo com Swales (2000), já nos cursos de graduação - onde os professores aqui investigados atuam - no Brasil, o inglês instrumental ganha lugar nos programas ao se vincular a áreas da Linguística aplicada (LA), como a Sociolínguística e Psicolinguística.

Assim, segundo Ramos (2005), o panorama para o inglês instrumental no Brasil se apresenta de forma positiva pelo fato de contribuir para formar cidadãos, bem como por atender às exigências do mercado de trabalho. Isto se dá porque, se por um lado o ensino de inglês em geral se preocupa em atender aos preceitos de aplicação de determinado método, na abordagem de cunho instrumental, em contrapartida, sempre foram levadas em consideração questões pertinentes ao papel, necessidades e anseios do aprendiz, papel do professor e papel do material didático. Isso pode ser observado em Celani (2005).

No entanto, mais do que conceituar ESP, historicizar o ensino de ESP no Brasil e apresentar alguns de seus pontos positivos, serão discutidos em detalhes na próxima seção algumas das perspectivas e desafios para este campo relacionados ao uso de tradução.

\section{4) Desafios e Perspectivas para Tradução no Ensino de ESP}

Embora o ensino de ESP no Brasil seja promissor e o ensino de tradução ofereça diversas vantagens em vários aspectos, como veremos nesta seção, a adoção dos dois em sala de aula não é um ponto pacífico. E é sobre isto que este tópico se propõe a discutir, trazendo à baila o embate de algumas vantagens e desvantagens do uso da tradução em aulas de línguas, que são as mesmas para ESP, para se tratar de forma mais específica.

Antes de adentrarmos nesta discussão, visto que já definimos ESP na seção anterior, vamos trazer uma breve conceituação de tradução. Alguns autores citados por Bomfim 
(2006), como Catford (1980) conceituam tradução como equivalência entre línguas diferentes quase sempre no nível das frases, enquanto outros como Leavult (1998) afirmam que tradução não é transpor palavras de uma língua para outra, mas transmitir conteúdo a um destinatário. Embora não haja consenso em relação à definição do que seja tradução, é possível perceber que um dos fatores importantes nesta discussão é a equivalência dos significados. Assim, é a partir de tal característica geral que esta pesquisa está embasada.

A discussão sobre as vantagens e desvantagens do uso da tradução em aulas de segunda língua (L2), segundo Stern (in Richards \& Rodgers, 1986) é antiga, uma vez que, no passado, muitos métodos sobre o ensino de L2 ditavam que a primeira língua (L1) deveria ser proibida no contexto de aprendizagem, pois acreditava-se que o emprego da tradução não era pedagógico, além de ser pouco comunicativo. Por outro lado, métodos como o Gramática-Tradução (MGT) buscavam compreender e usar a morfologia e sintaxe da língua alvo através da memorização de regras e fatos (Stern in Richards e Rodgers, 1986).

Corroborando esta perspectiva, Stoddart (2000, tradução nossa) postula que embora a tradução seja uma das grandes fontes que os professores tenham em mãos, ela é frequentemente descreditada por ser pouco comunicativa ou por focar apenas na precisão. Dessa forma, segundo ele, professores foram programados para perceber a tradução como uma prática de sala de aula "ruim". Algumas crenças, de acordo Ridd (2000), podem ter contribuído para se criar tal resistência ao uso de tradução não só em ESP como no ensino de inglês em geral, tais como: tradução se limita à leitura e escrita; por ser um processo lento, toma muito tempo da aula; entediante por ser uma correção problemática; professores não se sentem capacitados a ensiná-la por não terem sido capacitados a tal prática.

Reforçando as causas que podem ter levado professores a não adotarem tradução para o ensino de L2, Bonfim (2006) afirma que a única referência de grande parte destes profissionais é a legada pelo MGT, que subordinou a tradução à gramática separada do uso real da linguagem, e por isso torna-se um parâmetro negativo. Por consequência, vários métodos que vieram depois do MGT, tais como Método Direto, Audiolingual e Audiovisual, baniram o uso da língua materna do processo de ensino/aprendizagem, distanciando ainda mais o ensino de tradução da prática do ensino de línguas, como podemos notar em Bomfim (2006).

Segundo Leffa (1988), embora atualmente a Abordagem Comunicativa (AC) tenha sido amplamente adotada por propor o uso de material autêntico, e pelo fato de estar centrada no aluno (neste ponto converge com as bases do ensino de ESP), etc, ela ainda exclui rotineiramente a tradução como um de seus recursos, embora essa possa ser considerada uma quinta habilidade - juntamente com as outras quatro básicas (ouvir, falar, ler e escrever) - pois, de acordo com Bomfim (2006), funciona alternadamente em duas línguas de forma fluente, podendo ainda ser um recurso para se aprender a gramática, por 
exemplo. Entretanto, segundo Ross (2000, tradução nossa), recentemente, a atitude em relação à L1 e à tradução em aulas de línguas tem passado por uma mudança positiva.

De acordo com Stoddast (2000, tradução nossa), o campo da Línguística Aplicada tem dado substancial interesse para tradução e seus benefícios para aprendizes. Esse autor defende que ainda há muitas vantagens no uso de tradução como fonte de ensino de línguas, tais como: é ideal para o estudo do sistema linguístico; motiva aprendizes a pensarem sobre significados; o conhecimento de mundo dos aprendizes é expandido a partir da exposição da L2; pode ser usada em todos os níveis; é uma abordagem humanística (aprendizes podem seguir as lições); ao perceber por falta de equivalências linguísticas, semânticas e pragmáticas, aprendizes focam sua atenção na diferença dos dois sistemas linguísticos, desvendando, assim, alguns dos mistérios da L2, tais como a ordem das palavras ou distinção entre tempo e tense, por exemplo; pode proporcionar uma atividade integrativa das quatro habilidades; etc.

Ademais, outra vantagem do uso da tradução é o fato de que o aluno ganha autonomia à medida que ele aumenta sua fluência e diminui a recorrência à língua materna, disponibilizando, dessa forma, espaço para o desenvolvimento do senso crítico e de estratégias individuais de trabalho, como pode ser observado em Bomfim (2006). A mesma autora traz ainda duas outras considerações a respeito dos benefícios em relação ao ensino de tradução e o aluno de inglês instrumental. A primeira é o fato de que a tradução é uma ferramenta que pode contribuir para a redução de ansiedade do aluno, e a outra, é de que a crença dos professores acerca da tradução no ensino de ESP pode influenciar no aprendizado dos alunos.

Pesquisas realizadas por Upton \& Thompson (2001) conduziram ao fato de que aprendizes lançam mão da tradução mental quando esbarram em alguma dificuldade de compreensão. Convergindo com tal argumento, Atkinson (1992, tradução nossa) afirma que a tradução é uma das estratégias preferidas dos aprendizes, além de ser uma parte inevitável no processo de aprendizagem de uma segunda língua (L2) e, portanto, aprendizes traduzem e sempre traduzirão na sua língua materna (L1), não importa o quanto sejam reprimidos a não exercer tal prática.

Segundo Ross (2000, tradução nossa), corroborando as idéias de Upton \& Thompson e Atkinson, não importa o quanto aprendizes são bons em compreensão auditiva e em leitura autênticas, a maioria mantém tradução mental da L2 para L1 e vice-versa. Esse fato faz com que professores de línguas estrangeiras percebam a importância da tradução em salas de aula de línguas. Segundo J. Harmer (2001, tradução nossa), a principal causa para o uso da L1 é a sua presteza. Por exemplo, quando aprendizes são linguisticamente incapazes de ativar certo vocabulário para uma determinada tarefa, eles lançam mão da tradução. Outra razão, segundo este mesmo autor, é que a tradução é um processo natural no aprendizado de uma língua, e assim, a troca de código entre L1 e L2 é registrada como 
um desenvolvimento natural. Desse modo, se a tradução é inevitável, ela deve ser uma "aliada" e não uma "inimiga", defende Travaglia (2003).

Para Lynch e Hudson (1991), a tradução pode ser importante para alunos de cursos de ESP relacionados à ciência e tecnologia, pois para seu crescimento profissional terão, em geral, que discutir e aplicar conteúdos de materiais escritos em inglês. Os referidos autores sustentam seu argumento ao defenderem que alunos de inglês instrumental das referidas áreas não podem se limitar a simplesmente inferir significados, visto que precisam compreender precisamente o conteúdo sob pena de efeitos desastrosos. E tal perspectiva pode servir também para o estudo de EAP.

Assim, por motivos elencados nesta seção, é possível perceber que o uso de tradução nas aulas de ESP pode desempenhar um importante papel como ferramenta pedagógica para aquisição de uma língua estrangeira, uma vez que L1 assiste aos alunos durante o processo de aprendizagem. Por outro lado, algumas crenças por parte de professores a respeito dos efeitos da tradução podem resultar na negação de sua adoção para aulas de ESP. Algumas percepções de professores a respeito desse embate foram analisadas, e os resultados serão apresentados a seguir.

\section{5) Análise e Resultados}

Antes de apresentar a análise e os resultados, serão retomadas as questões de pesquisa: Quais são as crenças de professores de ESP que atuam no Brasil em relação ao uso de tradução em suas aulas? Quais as perspectivas para o uso de tradução em aulas de ESP? Portanto, o principal objetivo desta pesquisa foi identificar e analisar crenças e perspectivas de alguns professores que atuam no ensino de ESP no Brasil.

Para alcançar tal objetivo e responder às referidas questões, foram primeiramente selecionados seis professores de ESP que atuam em universidades federais de diferentes estados brasileiros para responderem aos questionários. Tal perfil foi eleito tanto pelo fato de atender aos anseios da pesquisa, quanto pelo fácil acesso dos pesquisadores a esses profissionais.

Em seguida, foi elaborado o questionário aplicado online sob a constante preocupação não apenas de responder às perguntas de pesquisa, mas também com questões éticas. E para isto, foi preparado um texto introdutório ao questionário informando ao respondente do seu anonimato na divulgação das respostas, oferecendo, assim, um ambiente mais confiável e confortável entre este e o pesquisador. Tal posicionamento segue em conformidade com os preceitos de Celani:

É preciso ter claro que pessoas não são objetos e, portanto, não devem ser tratadas como tal; não devem ser expostas indevidamente. Devem sentir-se seguras quanto a garantias de preservação da dignidade humana. Pode haver danos e prejuízos, também para 
os pesquisadores, em suas interações com colegas, com alunos de pós-graduação e com jovens iniciantes de iniciação científica. Para a profissão e a sociedade em geral, a perda de confiança na pesquisa e nos pesquisadores pode representar danos irreparáveis. (Celani, 2005, p.107).

Das perguntas aplicadas, as quatro primeiras, embora coadunem com o tema aqui proposto, foram mais gerais em relação ao objetivo da pesquisa e, buscaram, respectivamente, identificar os pesquisados com maior precisão, as habilidades comunicativas que usavam nos cursos, se lançavam mão de tradução em suas aulas, e quais metodologias/abordagens costumavam usar em consonância com o conteúdo aplicado. Já as últimas cinco perguntas tiveram fundamentos específicos, pois, buscaram responder pontualmente às perguntas desta pesquisa. Foram divididas em dois grupos, sendo três delas destinadas a identificar crenças em relação a possíveis vantagens e/ou desvantagens no uso de tradução em aulas de ESP; e as duas perguntas finais criadas com o intuito de coletar informações referentes às perspectivas e desafios para o ensino de ESP no Brasil.

Os resultados apontaram para o perfil dos entrevistados com experiência média de pouco mais de dez anos de ensino de ESP, sendo o professor menos experiente com exercício de quatro anos de profissão e o mais experiente com duas décadas, embora esse tenha atuado de forma esporádica durante este período. No entanto, mais importante do que os números é o fato de que a grande maioria declarou estar trabalhando de forma ininterrupta, o que indica que o perfil do corpo docente que respondeu ao questionário é formado por professores em plena atividade no ensino de ESP, embora um dos participantes tenha indicado que não está "trabalhando nessa área desde o segundo semestre de 2011" (respondente A).

Além dessa convergência, a maioria dos participantes também indicou - como já se esperava - que a habilidade linguística a ser trabalhada depende das necessidades da turma, embora a leitura e escrita fossem amplamente mais usadas do que a conversação e compreensão auditiva. Já em relação à prática do ensino de tradução em aulas de ESP, metade dos entrevistados respondeu que lança mão de tal ferramenta desde que se trate de ensino de EAP para alunos que objetivam aprovação em provas de proficiência de mestrado ou doutorado. No entanto, diferente de Bonfim (2006), nenhum dos participantes percebe a tradução como uma quinta habilidade, mas como uma ferramenta.

Em relação ao uso de métodos e abordagens, também como se esperava, os participantes indicaram as necessidades comunicativas dos aprendizes como norteadoras para a escolha da AC, MGT, etc. Tal estratégia coaduna com a definição do ensino de ESP de Dudley-Evans e St. John (1998), apresentada no terceiro item deste artigo. Contudo, uma das respostas chamou atenção por indicar pontualmente o uso da "abordagem instrumental segundo o concebido pelo Projeto Nacional de Inglês Instrumental e as novas concepções de linguagem/leitura sob a ótica da Linguística” (respondente B). Isso porque, 
embora o respondente esteja preocupado em adequar suas práticas ao contexto atual, o Projeto estabelecido na década de 1970 no Brasil, segundo Celani (1988), ainda funciona como referência metodológica para professores de ESP que atuam nesse país.

Já para gerar dados que pudessem responder pontualmente à primeira pergunta de pesquisa, "Quais as crenças de professores de ESP que atuam no Brasil em relação ao uso de tradução em suas aulas?", foram elaboradas perguntas que coletassem dados referentes à percepção dos professores em relação à aceitação do uso de tradução por parte dos aprendizes, vantagens e/ou desvantagens em se ministrar aulas de ESP integradas com tradução, e se a tradução seria uma ferramenta positiva ou negativa para o processo de ensino/aprendizagem de ESP.

Houve divergência nas respostas dos professores em relação à aceitação da tradução por parte dos aprendizes, pois alguns indicaram que estes não gostam, justificando que têm dificuldades com o uso da língua ou mesmo por não gostarem de leitura em geral. Outros professores informaram que seus alunos gostam de usar tradução no aprendizado de L2 por se sentirem mais seguros ou por entenderem melhor o conteúdo, e por consequência, conseguem se engajar melhor nas discussões. Um dos participantes nota ainda que apenas os alunos mais velhos gostam de ler: "Percebo que, quanto mais velhos são os alunos, mais necessidades de traduzir eles parecem ter. É como se somente com a tradução eles tivessem certeza de que estão compreendendo" (respondente C).

E um último professor justifica o gosto dos aprendizes pela tradução pelo fator linguístico natural, ou seja, a tradução é um processo natural no aprendizado de uma segunda língua. Tal perspectiva corrobora as ideias de J. Harmer (2001, tradução nossa), que defende o processo de tradução como um processo natural e motivado pela incapacidade linguística de ativar certo vocabulário para uma determinada tarefa. Assim, como dito no quarto item deste artigo, a tradução deve ser usada como um recurso útil no processo de ensino/aprendizagem de L2 já que não se pode evitá-la, defende Travaglia (2003).

Já a respeito das vantagens e desvantagens da tradução no ensino de ESP, a maioria dos professores afirma que a tradução pode ser vantajosa desde que utilizada com critérios e de forma a corresponder às expectativas dos aprendizes, e não atrelada aos conteúdos o tempo todo. Assim, os respondentes indicaram as seguintes vantagens para tradução no ensino de ESP: "a tradução pode favorecer uma maior interação com/entre a turma, dinamizando os usos da linguagem"; "pode trazer uma contribuição cultural"; "ganha-se tempo por não precisar usar tanto tempo para fazer com que os alunos entendam conceitos ou termos mais complexos na língua-alvo". Embora um dos professores tenha defendido este ganho de tempo como uma vantagem, um outro professor alerta "se a tradução for usada apenas como facilitadora, pode desfavorecer a manutenção necessária que a prática de linguagem requer". 
Dessa forma, é possível perceber que as vantagens descritas pelos professores transcendem as indicadas por Stoddast (2000) e apresentadas no quarto item deste artigo. Por outro lado, um dos professores foi contundente ao defender o uso de tradução em aulas de ESP como uma desvantagem: "não uso tradução nas aulas por não achar vantagem nisso. Acredito que o ensino de língua estrangeira não precisa de língua materna como canal". Lançando mão das ideias de Ridd (2000), é possível especular que este último professor possa estar rejeitando o uso de tradução por não se sentir capacitado para ensinar tal habilidade, por acreditar que tradução possa ser um processo lento, ou mesmo entender a tradução como limitada ao uso com leitura e escrita.

Esse último fator pode estar potencializado no contexto do Brasil pelo fato de o ensino de ESP ter sido implantado neste país a partir de tais características e, como descrito neste item, ainda serve de base para certas práticas de ensino. Ainda convergindo com as ideias de Ridd (2000), um dos respondentes indicou que a formação do professor é um dos fatores determinantes no sucesso do uso de tradução em aulas de ESP: "a prática vem demonstrando que a maioria dos profissionais não sabe lidar com a tradução no processo ensino/aprendizagem de ESP”.

Em relação aos desafios em ensinar tradução em aulas de ESP, os respondentes destacaram a subjetividade do autor na tradução e a formação do professor para lidar com este critério, pois "há muitas variáveis envolvidas com o objetivo da tradução" (respondente D). É preciso "selecionar critérios para o uso de tradução para que ela não se torne apenas um facilitador, mas um recurso para a construção contínua de saberes" (respondente $\mathrm{C}$ ).

Já a respeito das expectativas - respondendo aqui à segunda pergunta de pesquisa: Quais as perspectivas para o uso de tradução em aulas de ESP? - novamente as percepções não são unânimes. Por um lado, alguns respondentes acreditam que professores tendem a usar tradução no ensino de ESP por acreditarem ser um recurso útil: "muitos professores usam esse 'gênero' e não acredito que ele seja abandonado", "Vejo que muitos professores optam por usar esta prática em sala de aula como um recurso útil ao ensino de ESP. São poucos os que conheço que não a utilizam".

Por outro lado, outros professores têm a expectativa de abandono da tradução: "Acredito que há uma orientação formal no sentido de não haver tradução em sala de aula, por isso os professores podem ter a tendência de abandonar a tradução", "tenho visto um esforço para abandonar esta prática, focando nas estratégias de leitura e noção de gêneros textuais".

Se por um lado, professores acreditam que alunos, ou mesmo professores, têm dificuldade em tradução e que este recurso não é útil para o ensino de ESP, ou até mesmo atrapalha; por outro lado, outros professores percebem a tradução como um processo natural no aprendizado de uma segunda língua, uma ferramenta que ajuda a poupar tempo 
neste processo, ou seja, como uma aliada. E com base em tais percepções, as expectativas para o uso de tradução foram também divididas, ou seja, alguns respondentes acreditam que há uma certa tendência em lançar mão deste recurso em aulas de ESP por ser algo útil, mas outros participantes percebem um esforço em se abandonar esta prática.

Assim, embora as escolhas da metodologia/abordagem a ser aplicada e da habilidade linguística a ser mais desenvolvida em sala de aula estejam pautadas nas necessidades dos aprendizes, as percepções divergentes dos professores pesquisados em relação às crenças e perspectivas no uso da tradução em aulas de ESP reforçam o caráter polêmico deste tema.

\section{6) Considerações Finais}

Realizar pesquisas similares a esta, mas com professores menos experientes, com foco na percepção de alunos e/ou de pesquisadores, por exemplo, pode oferecer uma perspectiva possivelmente diferente, que somadas à apresentada neste trabalho e em outros com características convergentes, poderiam oferecer contribuições mais amplas e aprofundadas para os campos de conhecimento aqui investigados.

\section{Referências Bibliográficas}

ALESSI, Gelise Alfena; MARECO, Raquel Tiemi Masuda. "Inglês em Medicina Veterinária: Material de Apoio de Abordagem Instrumental”. In: Seminário do GEL, Ribeirão Preto, 57 , 2009. Disponível em: <http://www.gel.org.br/resumos_det. php?resumo=5829>. Acesso em: 30/08/2012.

ALLWRIGHT, Dick \& BAILEY, Kathleen. Focus on the Language Classroom: an introduction to classroom research for language teachers. Cambridge: Cambridge University Press, 1991.

ATKINSON D. Teaching Monolingual Classes. London: Longman, 1993.

BOMFIM, Rafaela. Babel de Vozes: Crenças de professores de inglês instrumental sobre tradução. Dissertação de Mestrado. UNB: Brasília, 2006.

BRANDÃO, Carlos Rodrigues. A pergunta a várias mãos: a experiência da pesquisa no trabalho do educador. São Paulo: Cortez, 2003.

BRUNER, Jerome. Atos de significação. Trad. Sandra Costa. Porto Alegre:Artes Médicas, 1997. 
CASTELLS, Manuel. A galáxia da Internet: reflexões sobre a internet, os negócios e a sociedade. Rio de Janeiro: Jorge Zahar, 2003.

CELANI, M. A. A. The Brazilian ESP Project: an evaluation. PUC/SP. São Paulo: EDUC, 1988.

et al. ESP in Brazil: 25 years of evolution and reflection. São Paulo: EDUC e Mercado de Letras, 2005.

CHIZZOTTI, Antonio. "A pesquisa qualitativa em ciências humanas e sociais: evolução e desafios”. Revista Portuguesa de Educação, Braga, vol. 16, n², p. 221-236, 2003.

DUDLEY-EVANS, T. \& St. JOHN, M.J. Developments in English for specific purposes: A multi-disciplinary approach. Cambridge: CUP, 1998.

ERICKSON, Frederick. "Ethnographic description". In: AMMON, H.U.; DITTMAR, N.; MATTHEIER, K./J. Sociolinguistics. Berlim: Walter de Gruyter, 1988.

LEFFA, Vilson J. "Metodologia do ensino de línguas". In: BOHN, H. I.; VANDRESEN, P. Tópicos em linguística aplicada: $O$ ensino de línguas estrangeiras. Florianópolis: Editora da UFSC, 1988.

LUDKE, M. ; ANDRÉ, M. . Pesquisa em Educação: Abordagens Qualitativas.São Paulo: EPU, 1986.

MAGALHÃES, Maria Cecília. "Etnografia colaborativa e desenvolvimento de professor". Trabalhos de Lingüística Aplicada: Campinas. 1994.

MCDONOUGH, J. \& MCDONOUGH, S. What is Research: Research Methods for English Language Teachers. London: Edward Arnold, 1997.

PAIVA, Vera Lúcia M. de O. e. "Reflexões sobre ética e Pesquisa". Revista Brasileira de Lingüística Aplicada. Belo Horizonte. V.5, n.1, p 43-61, 2005.

RAMOS, R.C.G. "Instrumental no Brasil: a desconstrução de mitos e a construção do futuro". In: FREIRE, M.M.; ABRAHÃO, M.H.V.; BARCELOS, A.M.F. (Orgs.) Linguística Aplicada e Contemporaneidade. São Paulo: Pontes, 2005.

RICHARDS, Jack C. \& RODGERS, Theodore S. Approaches and methods in language teaching: A description and analysis. Cambridge: Cambridge University Press, 1986.

ROSS N. J. 2000. "Interference and Intervention: Using Translation in the EFL Classroom”. Modern English Teacher, n 9(3). p. 61-66, 2000. 
SILVA, Francisco Borges. "Contribuições Linguísticas: dos Estudos Saussurianos aos estudos modernos". Revista Travessias: Educação, Cultura, Linguagem e Arte, Curitiba, v.2 n.2., 2008.

SPRADLEY, James. The ethnographic interview. Stamford: Thomson Learning, 1979.

STODDART, Jonathan. "Teaching through translation". The British Council Journal, London, $\mathrm{n}^{\circ}$. 11, April, 2000.

SWALES, John M. "ESP comes of age? - 21 years after: some Measurable Characteristics of Modern Scientific Prose". Unesco-LSP Newsletter, Denmark, vol.7, n.2., 1984.

Cambridge, v.20, 2000.

."Language for Specific Purposes". Annual review of applied linguistics,

UPTON,T.A. \& THOMPSON, L.C.L. "The role of the first language in second language reading". Studies in Second Language Acquisition, Estados Unidos, v.23, 2001.

ANEXO

\section{Questionário Online}

Prezado Professor (a),

Este questionário faz parte de uma pesquisa que tem por objetivo investigar a relação entre o ensino de tradução e ESP. Responda sinceramente às perguntas abaixo e sinta-se à vontade para fazer qualquer comentário pessoal ou profissional que julgar relevante, pois o anonimato é garantido. Assim que possível, apresentaremos os resultados da pesquisa a você.

Agradecemos desde já a sua contribuição,

Profa. Carla Alecsandra (UFPB) e Prof. Marcus Mussi (UFRJ)

1. Há quanto tempo você ensina ESP?

R.:

Quais habilidades comunicativas (escrita, fala, auditiva, leitura) geralmente você ministra em suas aulas?

R.:

3. Você costuma adotar técnicas de tradução em suas aulas de ESP? 
R.:

4. Quais metodologias e/ou abordagens você costuma adotar em suas aulas?

R.:

5. Você acredita que seus alunos gostam de traduzir? Por quê?

R.:

6. Quais vantagens e/ou desvantagens em ministrar aulas de ESP integradas com tradução?

R.:

7. Em sua opinião, você acredita que o ensino de tradução atrapalha ou ajuda o processo de ensino/aprendizagem de ESP? Por quê?

R.:

8. Você acredita que professores tendem a usar ou abandonar o ensino de tradução em ESP no Brasil? Por quê?

R.:

9. Em sua opinião, há desafios em ensinar tradução em aulas de ESP no Brasil? Quais seriam?

R.: 